\title{
Ethical Allocation of Preexposure HIV Prophylaxis
}

Lawrence O. Gostin

Georgetown University Law Center, gostin@law.georgetown.edu

Susan C. Kim

Georgetown University Law Center, sck3@law.georgetown.edu

Georgetown Public Law and Legal Theory Research Paper No. 11-16

This paper can be downloaded free of charge from:

https://scholarship.law.georgetown.edu/facpub/502

http://ssrn.com/abstract=1743593

305 JAMA 191-192 (2011)

This open-access article is brought to you by the Georgetown Law Library. Posted with permission of the author. Follow this and additional works at: https://scholarship.law.georgetown.edu/facpub

Part of the Health Law and Policy Commons, and the International Law Commons 


\section{Ethical Allocation of Preexposure HIV Prophylaxis}

Lawrence O. Gostin, JD

Susan C. Kim, JD, MPH

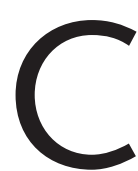

IVIL SOCIETY-LED MOVEMENTS TRANSFORMED GLOBAL AIDS action from deep skepticism about extending antiretroviral (ARV) treatment in low- and middle-income countries to a historic scaling up of treatment toward universal access. During its first phase (2003-2008), the US President's Emergency Plan for AIDS Relief (PEPFAR) - the largest national commitment to combat a single disease-supported treatment for more than 2 million people, care for more than 10 million people, and prevention of mother-to-child transmission in 16 million pregnancies. ${ }^{1}$ The Global Fund to Fight AIDS, Tuberculosis and Malaria (Global Fund), a unique international financing institution, has committed $\$ 19.3$ billion in 144 countries to support large-scale prevention, treatment, and care, with most resources devoted to AIDS treatment. ${ }^{2}$

The AIDS movement, however, is at an inflection point due to the interplay of key health and economic determinants - the global financial downturn, tight foreign aid budgets, and intense resource competition. Even with historic global engagement, human immunodeficiency virus (HIV) treatment is insufficient in resource-poor settings. Although 5.2 million individuals currently receive treatment for HIV infection, 10 million more are in immediate need and $64 \%$ of those in need live in low- and middle-income countries. ${ }^{3}$ PEPFAR's fiscal-year 2011 budget proposes only a $2 \%$ increase, which will result in future treatment enrollment freezes and a growing waiting list among 14 million treatment-eligible individuals. ${ }^{4}$ Similarly, Global Fund pledges reached only $\$ 11.7$ billion for 2011-2013, failing to meet the fund's lowest "austerity-level" target of $\$ 13$ billion-the amount needed to sustain current treatment rates. ${ }^{5}$ A report by the Institute of Medicine concluded that because treatment can only reach a fraction of those in need, it is "not sustainable for the foreseeable future." 6

Policy makers will now have to consider implementing a new intervention, ie, preexposure prophylaxis (PrEP). Recent studies suggest that PrEP could mean a shift of ARVs from treatment to prevention. For instance, the iPrEx study found that men who have sex with men (MSM) taking tenofovir/emtricitabine were $44 \%$ less likely to become infected with HIV than those taking a placebo. ${ }^{7}$ The CAPRISA 004 trial (a proof-of-concept study) found that vaginal tenofovir disoproxil fumarate gel reduced the risk of contracting HIV by $39 \%,{ }^{8}$ and the CDC 4323 study (an extended safety study) confirmed that oral tenofovir disoproxil fumarate was safe for use as PrEP in MSM. ${ }^{9}$ Although it will take several years to fully establish the clinical efficacy of PrEP in varying populations, these encouraging early results have accelerated global dialogue on its proof of deliverability.

\section{PrEP Clinical Trials}

The principle underlying PrEP is that ARVs could prevent HIV infection among individuals who are HIV negative and at high risk. PrEP does not involve getting permission from a partner, so it could be especially valuable for individuals who cannot use condoms because they sell sex, are in danger of rape, or are under pressure to have sex. As of November 2010, there were 8 ongoing or planned PrEP clinical trials using tenofovir disoproxil fumarate, tenofovir disoproxil fumarate gel, or tenofovir/emtricitabine in Africa, South America, Thailand, and the United States. The studies encompass diverse populations, including injecting-drug users, MSM, serodiscordant heterosexual couples, and sex workers.

These studies will be completed at different times, raising the question that if a trial demonstrates effectiveness for a given study group, should PrEP be used for others? For example, if data prove PrEP sufficient for regulatory approval in MSM, would it be unethical to fail to offer PrEP to HIV-negative partners in heterosexual serodiscordant couples? In other words, are the biological pathways sufficiently similar to convincingly suggest that PrEP should be offered to at-risk populations who could benefit without having specific data for that risk group?

Unlike existing prevention strategies such as voluntary counseling and testing, condoms, and male circumcision, PrEP is a continuous biomedical intervention. Although prevention of mother-to-child transmission also uses ARVs, it can be accomplished in a discrete time framecombination therapy during the months around delivery can reduce perinatal transmission by more than $90 \% .{ }^{10}$ Under what circumstances is it ethical to recommend that healthy

Author Affiliations: O'Neill Institute for National and Global Health Law, Georgetown University Law Center, Washington, DC.

Corresponding Author: Lawrence O. Gostin, JD, O'Neill Institute for National and Global Health Law, Georgetown University Law Center, 600 New Jersey Ave NW, Washington, DC 20001 (gostin@law.georgetown.edu). 
individuals take medications with potential adverse effects and drug resistance? Moreover, PrEP is not likely to be a population-wide intervention. Rather it will be a targeted intervention within a larger combination prevention strategy for at-risk populations. Given intense resource scarcity, how can policy makers make difficult choices among equally important interventions?

\section{Ethical Allocation}

The ethical issues raised by PrEP are difficult, but not insurmountable. The following guidance could help ensure ethical allocation under circumstances of scarcity.

Comparative Cost-effectiveness. If a salient goal is to maximize lives saved, it is essential to adopt strategies to achieve that goal. Treatment alone clearly will not stem the AIDS pandemic: for every 100 individuals who are presumed to be receiving treatment each year, 200 become infected. ${ }^{3}$ Comparative cost-effectiveness research, therefore, should inform policy (1) regarding one prevention vs another prevention-which interventions work best, in what combination, and at what cost? (2) regarding prevention vs treatment-would the use of ARVs for prevention provide more benefit than treatment at less cost, or is the cost per infection averted greater than the cost of treatment? and (3) regarding one treatment vs another treatment-would the use of ARVs for prevention induce resistance to first-line treatment, requiring significantly more expensive second- or third-line pharmaceuticals? In assessing the costs and benefits, policy makers should take a long-term perspective. Initial costs for PrEP could save health systems significant resources over time. UNAIDS is currently coordinating a larger effort to model health outcomes and comparative cost-effectiveness to address these questions.

Values beyond cost and benefit also may be considered. Should priority be given to those already in treatment because it would be a hardship to discontinue their medication? Or are all treatment-eligible individuals equally deserving of a fair chance for treatment? Moreover, should priority be given to the most marginalized populations, such as MSM, injecting-drug users, or sex workers, because they have suffered compounding disadvantages?

Good Governance. International principles of good governance require policy makers to act transparently, engage relevant stakeholders, and be held accountable. Policy makers must make clear the reasons for, and provide evidence supporting, their decisions. Stakeholder engagement ensures that the voices of affected communities are heard. Additionally, policy makers should be held accountable for fair deliberation and ultimately success.

Access Barriers. Affected communities face multiple obstacles in accessing services. Cost remains a key barrier, requiring financial support from external sources. There also exist numerous noncost barriers such as discrimination, criminalization, privacy invasion, and onerous consent laws for young individuals. Overcoming barriers requires review and revision of laws to ensure that governments protect the human rights of persons living with HIV/AIDS.

\section{Quality Improvement}

If countries implement PrEP, they should continuously monitor, evaluate, and improve services in ways that are community-specific. Risk profiles change (eg, drug resistance and toxicity), as does the evidence base for interventions. Ethical issues are not static but will fluctuate based on evolving research and surveillance. For example, if PrEP speeds the evolution of drug resistance or if individuals increase risk behavior (neither of which occurred in the iPrEx study), policy makers would need to alter their treatment recommendations.

Resource restraints will remain a pressing challenge for the foreseeable future. The AIDS movement is at a pivotal point in history, where it will face scrutiny not only to demonstrate that interventions are cost-effective and equitably distributed, but also to balance resource demands with other global health imperatives, such as maternal/child health, noncommunicable diseases, and the human resources and infrastructure required to ensure the health of individuals and communities.

Conflict of Interest Disclosures: All authors have completed and submitted the ICMJE Form for Disclosure of Potential Conflicts of Interest and none were reported.

Funding/Support: This work received support from a grant to study PrEP implementation from the Bill \& Melinda Gates Foundation.

Role of the Sponsor: The funding organization had no role in the preparation, review, or approval of the manuscript.

Additional Contributions: We thank the co-investigators in the ongoing grant: Mark R. Dybul, MD, O'Neill Institute for National and Global Health Law, Georgetown University/George W. Bush Institute, Dallas, Texas; Peter Piot, MD, PhD, FRCP, London School of Hygiene and Tropical Medicine; Geoffrey Garnett, PhD, Imperial College London; and Andreas Eisingerich, PhD, Imperial College London. Dr Dybul also provided helpful revisions to the manuscript, for which he did not receive compensation.

\section{REFERENCES}

1. Gostin LO, Mok EA. The President's Global Health Initiative. JAMA. 2010; 304(7):789-790.

2. About the Global Fund. The Global Fund to Fight AIDS, Tuberculosis and Malaria. http://www.theglobalfund.org/en/about. Accessed November 19, 2010. 3. Report G. UNAIDS Report on the global AIDS epidemic. UNAIDS. http://www .unaids.org/globalreport/Global report.htm. Accessed November 26, 2010.

4. Executive summary of PEPFAR's strategy. US President's Emergency Plan for AIDS Relief. http://www.pepfar.gov/strategy/document/133244.htm. Accessed October 19, 2010.

5. McNeil DJ Jr. Global fight against AIDS falters as pledges fail to reach goal of $\$ 13$ billion. New York Times. October 5, 2010:A10.

6. Institute of Medicine. Preparing for the Future of HIVIAIDS in Africa: A Shared Responsibility. Washington, DC: National Academies Press; 2010.

7. Grant RM, Lama JR, Anderson PL, et al; the iPrEx Study Team. Preexposure chemoprophylaxis for HIV prevention in men who have sex with men [published online November 23, 2010]. N Engl J Med. doi:10.1056/NEJMoa1011205.

8. Abdool Karim Q, Abdool Karim SS, Frohlich JA, et al; CAPRISA 004 Trial Group. Effectiveness and safety of tenofovir gel, an antiretroviral microbicide, for the prevention of HIV infection in women. Science. 2010;329(5996):1168-1174.

9. Preliminary results from first safety study of daily tenofovir for HIV prevention among MSM find no significant concerns. US Centers for Disease Control and Prevention. http://www.cdc.gov/nchhstp/newsroom/MSMPrEPMediaSummary .html. Accessed October 19, 2010.

10. Dabis F, Bequet L, Ekouevi DK, et al. Field efficacy of zidovudine, lamivudine and single-dose nevirapine to prevent peripartum HIV transmission. AIDS. 2005; 19(3):309-318. 